AUTHOR:

Kobus Marais ${ }^{1}$

Carmen Delgado Luchner ${ }^{1,2}$ (D)

AFFILIATION:

${ }^{1}$ University of the Free State

${ }^{2}$ University of Geneva

EMAIL:

jmarais@ufs.ac.za;

carmen.delgado@unige.ch

DOI: https://doi.org/10.38140/

jtsa.1.4335

Journal for Translation

Studies in Africa

2020 (1): 1-6

PUBLISHED:

22 May 2020

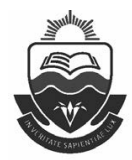

Published by the UFS

http://journals.ufs.ac.za/index.php/itsa

(1) Creative Commons

With Attribution (CC-BY)

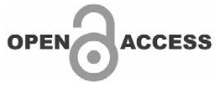

\section{TRANSLATION STUDIES IN AFRICA: QUO VADIS?}

We can understand if you feel somewhat let down by the topic of this editorial. You would be correct in asking whether one should not have figured out the direction of a field of study before starting a new journal on an undecided agenda. "Don't you know what you want to publish?" you might rightfully ask.

Well, yes and no. We know what we want to achieve with the journal, or rather, we know what role we want the journal to play. However, that does not mean that we are - or should be - sure where the field is going - in Africa. Furthermore, asking whereto for translation studies in Africa does not necessarily imply that there is no direction or nowhere to go. Rather, we are wondering which of the many possible directions translation studies will - or should - take on the continent.

So, should we just sing along with "Que sera sera" what will be will be? Or should we try to influence the field in some way? Do we engineer a direction for the field of study, or do we leave it to develop organically? Is either of the two options possible, or is there something else that we should attempt? Furthermore, the continent has been subjected to so much trauma and social experimentation that we cannot help wonder whether another effort to "steer Africa in the right direction" is advisable.

We, and most probably some other colleagues too, are caught between an activist mindset that wants to set and work towards a coherent research agenda for the field of translation studies in Africa and a non-interventionist mindset that would prefer things to sort themselves out. The first Summer School for Translation Studies in Africa in 2009 stands as one of the first (though neither the first nor the only) efforts to think about the concept of translation in Africa. A subsequent series of Summer Schools have led to the formation of the Association for Translation Studies in Africa in 2016 in Nairobi, Kenya, which in turn has led to the founding of the Journal for Translation Studies in Africa of which you now read the editorial to the inaugural volume. After more than 10 years of engaging scholars from all over the world, but particularly Africa, on this topic, we are still not sure that we understand the constraints that translation studies scholars face on the continent - and if we do, whether we or anybody else can make that much of a difference. 
So, perhaps a journal is the best way for both intended and unintended trends to emerge. On the one hand, the journal would offer scholars working on issues pertaining to translation in Africa the opportunity to interact with one another, and out of this interaction, some agenda might emerge. On the other hand, it might be that no specific agenda emerges but that scholars just interact with one another - and that the debate itself is a way of gradually defining the contours of this field of research in Africa. That said, this first edition of JTSA, under guest editorship of Carmen Delgado Luchner, reflects an attempt on our part to start the scholarly debate by steering it in a specific direction, namely a focus on Africa as a developmental context in which to study translational phenomena and practices. We view this perspective as relevant for translation studies in Africa and as a potential key differentiator between the kind of translation practices found in Africa and elsewhere. Whether other scholars on the continent - or working on the continent - will agree is open for debate.

In the end, even though we (the editorial team and current guest editor) might have our own ideas about how translation in Africa should be studied, what we aim to create in this journal is above all a space for a dialogue between scholars working on translation issues in Africa. Even if we wanted to, we - or the journal or anybody else - would not be able to control and predict the trajectory that translations studies in Africa will take over the next decades. Attempting to do so by limiting the scope of the debate from the outset would indeed be detrimental because new developments that we cannot currently anticipate but that might decisively shape translation practice and thinking in Africa would remain excluded from the debate. Thus, a balance must be found between achieving a general sense of direction (or purpose) and allowing for organic growth.

We hope that this journal will provide a platform for scholars to engage and determine their own way forward, knowing full well that the path is not linear and might sometimes take us back rather than forward. What we hope for is that we engage one another in robust debate where we do not pull intellectual punches about translation issues as they pertain to Africa. We hope that the journal becomes a space for dialogue and that dialogue would result in what it results in - a research agenda, no research agenda, multiple research agendas?

In our view, the relative success of translator training in a number of African universities is probably one of the biggest threats to the development of a research agenda for translation studies in Africa. This might seem paradoxical since it is after all often through training that translation studies enters academia. However, most of the training is based on what could be regarded as "common wisdom" in the industry rather than being informed by contextrelevant research. Precisely because these training programmes have been so successful and because they are enabling some of their graduates to access high-level jobs, there seems to be little interest in questioning the foundations on which they are built. This means that translation studies in Africa is caught up in a vocational training approach. If one looks at the curricula for training, it seems that developments in translation studies after the linguistic paradigm have largely passed these institutions by, and there is no discernible difference between the assumptions underlying the training of, for instance, Swahili-English translators in Nairobi and that of English-French translators in Geneva. Apart from some awareness of the role of culture in translation, existing curricula pay scant attention to historical, sociological, ideological and power issues in translation - those issues that have been highlighted over the past three decades. And yet, anyone who has researched translation phenomena on the African continent knows that language use in Africa is inherently political, much more so than in other parts of the globe. The historical events that have shaped current language 
policies and practices in Africa differ considerably from those that have led to the emergence of largely monolingual nation states in Europe. The co-existence of former colonial languages, large vehicular languages and smaller local languages in the same geographic territory and the hierarchical distribution of language skills within African societies (where a high level of mastery of the colonial language is still often the privilege of the elites) makes translation between those different languages inherently asymmetrical and closely intertwined with existing power structures. Students who are not prepared to think about these aspects during their training might be ill prepared for the market.

Furthermore, technology is predominantly taught as a skill to enhance interlingual translation with little thinking about digital humanities and the multimodality implications of recent developments in communication technology. The unique patterns of media consumption and media distribution found in Africa open a relevant and currently underexploited field of study for translation scholars. While translation of literary works has been given considerable attention, the same cannot be said of the media produced and consumed by an arguably much higher proportion of individuals in Africa (and in the world): Nollywood films, local sitcoms, multilingual content circulating on social media. The informal nature of some distribution channels might make them more difficult to study for translation scholars - yet this assessment in itself would be a valuable insight for which we currently lack empirical studies.

The limitations mentioned above are linked to another concern for translation studies in Africa, namely its dependence on the rest of the world. Because literary translation has enjoyed a high status in the rest of the world, translation studies students and scholars in Africa tend to work mainly, though not exclusively, on literary translation. Because interlinguistic translation has been the dominant mode of thinking about translation elsewhere, translation studies scholars in Africa have followed that trend. Because translation studies elsewhere studies the formal economy, translation studies scholars in Africa have ignored the vast domain (between $30 \%$ and $70 \%$ of the economies of Sub-Saharan Africa) of the informal economy in their research.

Paradoxically, this occurs at a time when translation scholars in the West are developing an increasing interest in precisely those phenomena that are abundant in Africa: informal community translation practices, multilingual communication on social media, fansubbing of nonmainstream movies and series, the use of new technologies, multimodality, and empowerment through translation. This further cements the divide between translation studies as taught and practiced in Africa and elsewhere.

The lack of resources on the continent does of course play a major role in limiting research and preventing institutions from implementing the latest pedagogical models. Internet connections are not dependable - if existent. Libraries are stocked with dated works - if at all. Data is expensive, relatively speaking, and students (and universities) are poor. When students work under these constraints, they inevitably find it difficult to get up to date let alone compete with colleagues from across the globe. One of the things that scholars on the continent may want to think about is ways to obtain and distribute reading material. Publishing our own material is not necessarily a solution - because of the lack of resources but also because of the danger of creating an insular system of thought and reinventing the wheel within a given discipline. Whichever way one thinks about this, it is incumbent on scholars involved in translation studies in Africa to work towards solving these problems.

This inaugural special edition of JTSA presents papers from a panel on translation and development that was hosted at the $6^{\text {th }}$ IATIS conference in Hong Kong in 2018. The panel 
brought together scholars working with Hilary Footitt in the UK on the "Listening Zones" project and other scholars from around the world who are working on translation and development with the following call:

The majority of the world's population lives in emerging or developing countries. Most of these countries are highly multilingual and present a wealth of institutionalised and informal translation and interpreting (T\&l) practices. In settings where many citizens have limited mastery of the official language of their country, translation can play an important developmental role by contributing to the emergence of shared representations and social forms. This role can only be understood by adopting a non-reductionist perspective that takes into account the plurality of cultural, political and economic factors that influence how populations experience development.

However, compared with industrialised market-economy countries (IMEC), developing countries also generally experience acute limitations of skills, material and financial resources. This has implications for the practical implementation of multilingualism and the potential for professional T\&I. National governments, multilateral organisations and foreign donors have been trying to address these limitations through a variety of national development initiatives and international aid. Development work has in turn given rise to its own practices of translation, interpreting and cultural mediation, including monolingual practices of "translation" of local reality into international "development speak". Nongovernmental organisations (NGOs), in particular, have placed increasing emphasis on participatory development approaches, which rest on their ability to communicate successfully across the linguistic and cultural divide that often separates them from project beneficiaries.

This interdisciplinary panel aims to establish a dialogue between translation studies, development anthropology, international relations and cultural studies in order to address the nexus between translation/interpreting and development from three complementary angles: theory, practice and pedagogy. Contributors will discuss the importance of translation in the social transformations developing countries are experiencing, the specific translation practices produced by development projects and the implications for translator and interpreter training in development contexts.

From a high number of abstracts and preliminary submissions, ultimately three papers made it through all stages of the peer review process and were accepted for this issue. Two recent $\mathrm{PhD}$ graduates also submitted summaries of their $\mathrm{PhD}$ theses that both relate to the topic of the special issue. Together, these texts provide the reader with a good overview of current thinking on translation and development. Two papers reporting on the practices of development NGOs in a variety of contexts (Tesseur \& Crack; Delgado Luchner) shed light on real-life social-cultural practice in Africa - and other Global South contexts. Another paper considers the influence of intersemiotic translation on helping development practitioners to understand the meaning of the development practices in which they try to engage (Marais). The doctoral dissertations focused on translation practices in South African community radio stations (Van Rooyen) and the adaptation of public health messages in Zambia (Chibamba), both taking into account the opportunities and constraints created by the development context in which these practices were embedded. The inaugural issue includes an opinion piece on a translational turn in Africa by Paul Bandia, president of the Association for Translation studies in Africa. It also boasts a review by Monnapula Molefe of the book Translation and Public Policy: Interdisciplinary Perspectives and Case Studies, edited by Gabriel González Núñez and Reine Meylaerts. 
Because of the constraints on translation studies scholars, on which we reflected in various ways above, the success of this journal is not a foregone conclusion. It is in the hands of scholars working on African translation studies issues to make it a success. Yet while the journal itself will play a developmental role, and has specific subsections for exactly this aim, being aware of the challenges that African scholars face does not mean compromising on quality. Such a compromise would mean risking to enforce and contribute to a two-tier system to scholarship that is ultimately harmful to African universities and scholars, as it leads to their not being taken seriously on the world stage. For this reason, the journal will start out with one issue per year and with as few as the three papers of this edition. For the same reason, the journal publishes open-source papers that should be available to all scholars on the continent, irrespective of financial ability. If translation studies scholars working on African issues roll up their sleeves and produce solid research, we shall surely expand on the issues to provide opportunities.

So, we are putting this journal together to allow translation studies scholars to engage one another in a spirit of dialogical and robust hospitality. The editorial team does not have an agenda, but we do have a vision for the journal, namely:

To offer a high-level publication outlet to translation-studies scholars from Africa, African translation-studies scholars in diaspora and scholars in general working on African topics in translation studies to disseminate their work in order to advance the field of translation studies in Africa and to position Africa in relation to the rest of the world as far as translation studies is concerned.

In order to achieve this vision, the editorial team, together with ATSA's board, set out the following scope:

JTSA promotes the scholarly study of translational phenomena in the widest sense of the word, including intralingual, interlingual and intersemiotic translation, and values interpreting and translation equally. It welcomes interdisciplinary research, including but not limited to interpreting studies, multimodality and multimedia studies, development studies, media studies, cultural studies, political science, sociology and history. Contributions can be theoretical, empirical or applied. The journal is looking for cuttingedge research while keeping open a section for developing scholars, namely the 'New Voices' section. The 'Reviews' section focuses on introducing books with a focus or relevance to the journal's African agenda. An 'Agenda' section will focus on opinion pieces concerning aspects of translation studies as it pertains to the African content.

To assist us with strategic decision-making, the following members have been appointed to the International Advisory Board of JTSA from 2018 to 2023:

- Prof Rita Kothari (Ashoka University)

- Prof Reine Meylaerts (KU Leuven)

- Prof John Milton (University of São Paulo)

- Prof Jacobus Naude (University of the Free State)

- Prof Maria Tymoczko (University of Massachusetts, Amherst)

- Prof Rita Wilson (Monash University)

In addition to the above, JTSA also worked out a language policy to do justice to the pervasive multilingualism in Africa. The editorial team invite authors and readers to share their views on this language policy with us. JTSA's language policy is informed by two principles. 
Firstly, the journal would like to recognize and allow expression of multilingualism. Secondly, the journal would like to promote pan-African intellectual dialogue as well as dialogue within a global community of scholars. To provide for both these principles, JTSA adopts the following policy, based on translation:

1. JTSA publishes full papers in English.

2. Peer review is performed in English on the English texts.

3. JTSA publishes abstracts in any African language (including Arabic) as well as in French and Portuguese.

4. JTSA publishes translations, into any African language (including Arabic) as well as French and Portuguese, of accepted English texts in a separate section, for authors who want to use this option.

a. Translations are provided by the author, at the author's cost, and the quality of the translation is the responsibility of the author.

b. If the quality of the translation is not acceptable to the editorial team its publication will be rejected and the publication of the paper might be delayed.

At this first issue, we thank the Vice-rector: Research, Prof Corli Witthuhn, and the Directorate: Research Development at the University of the Free State for taking financial responsibility for the production costs as well as for making available an online journal system and technical expertise to help set up the journal and its submission system. The URL to the journal's web site is as follows: http://journals.ufs.ac.za/index.php/itsa/login. This web site has all other relevant information for authors, reviewers and libraries.

Apart from peer-reviewed scholarly papers, JTSA also publishes book reviews, opinion pieces and work by young scholars. The editor in chief is assisted by three sub-editors, who each takes responsibility for one of the sections:

- Dr Francis Ajayi - Agenda (Opinion pieces)

- Dr Felix Awung - Reviews

- Dr Mwamba Chibamba - New Voices (Young scholars)

So, will this journal be a success? How long will it last? Will scholars choose to publish in it?

We do not know. As editorial team and in terms of planning by the ATSA board, we have and will do our best to make it a success. However, we are dependent upon scholars submitting quality papers for the journal to succeed. The trajectory that will emerge for this journal lies in many hands. 